\title{
Modelo de portal para socialização de conhecimentos científicos na UFG
}

\begin{abstract}
Ana Flávia Pereira dos Santos
Roberto da Piedade Francisco

Mestranda em Administração Pública. Universidade Federal de Goiás (UFG) - Brasil. anaflavia.santos@gmail.com

Doutor em Engenharia de Produção. Universidade Federal de Goiás (UFG)-Brasil. roberto.piedade@ufg.br
\end{abstract}

João Batista de Lima Filho
Graduando em Engenharia de Produção. Universidade Federal de Goiás (UFG) - Brasil. jfilho_7@hotmail.com

\section{RESUMO}

O estudo apresentado neste artigo buscou compreender como a Universidade Federal de Goiás (UFG) transmite à sociedade os conhecimentos científicos gerados pela Instituição e propor um Modelo de Portal na internet que possa ser utilizado pela Universidade para impulsionar o trabalho de socialização de sua produção científica. A pesquisa foi realizada em documentos institucionais, nos sites das estruturas centrais e de comunicação da UFG e constatou que, apesar da Instituição ter diretrizes e desenvolver ações e atividades em favor da difusão científica, existem lacunas nesses processos, sobretudo porque as iniciativas ocorrem de maneira isolada e fragmentada. A partir da análise de experiências desenvolvidas em outras instituições de ensino superior e da observação do ambiente interno da UFG, concluiu-se que a estruturação de um Portal para Ciência na UFG pode cumprir a função de reunir conteúdos e articular os vários atores envolvidos no trabalho de fazer circular os resultados das pesquisas científicas realizadas na Universidade, se configurando em um instrumento capaz de ampliar, democratizar e dar maior visibilidade aos saberes produzidos na Instituição.

Palavras-chave: Divulgação Científica. Socialização do Conhecimento Científico. Modelo de Portal. Popularização da Ciência. Pesquisa e Universidade.

\section{A website model for socialization of scientific knowledge in the UFG}

\begin{abstract}
This paper sought to analyze how the Federal University of Goiás (UFG) disseminates the scientific knowledge generated by the Institution and then, present a Website Model that can be used by the University to promote the work of socializing its scientific production. The research was conducted in institutional documents, on the websites of the central and communication structures of the UFG and found that, although the Institution has set guidelines and develops actions and activities in favor of scientific diffusion, there are gaps in these processes, especially because the initiatives occur in an isolated and fragmented manner. Based on the analysis of experiences developed in other institutions of higher education and the observation of the internal environment of the UFG, it was concluded that the structuring of a Website for Science in the UFG can fulfill the function of gathering contents and articulating the various actors involved in the work of disseminating the results of scientific research done at the University, thus becoming an instrument capable of expanding, propagation and giving greater visibility to the knowledge produced in this Institution.
\end{abstract}

Keywords: Scientific dissemination. Socialization of scientific knowledge. Website Model. Popularization of science. Research and University. 


\section{INTRODUÇÃO}

A comunicação científica, ou seja, a circulação de conteúdos científicos entre pesquisadores, é fundamental na medida em que responde a perguntas específicas e permite que cientistas obtenham informações sobre pesquisas de sua área de interesse e entendam outras áreas, podendo ampliar seus campos de estudo. Além disso, é na comunicação dos resultados das pesquisas científicas que as descobertas podem se tornar mais confiáveis porque outros pesquisadores proporcionam visões críticas aos trabalhos desenvolvidos (KAPLAN; STORER, 1968 apud MUELLER, 1995).

Entretanto, na contemporaneidade, os argumentos em defesa da publicização dos resultados de pesquisas científicas vão além da necessidade de validação dos estudos entre os pares. A transmissão de conhecimentos científicos à sociedade em geral, na denominada divulgação científica, é apontada como uma prerrogativa da democracia, uma forma de prestação de contas, uma demanda do capitalismo, um direito do cidadão (PEREIRA, 2012; CASTELFRANCHI, 2008).

Sendo assim, organizações públicas de ciência e tecnologia (C\&T), universidades, institutos de pesquisa, fundações de apoio, secretarias e ministérios precisam desenvolver um trabalho eficaz e continuado de difusão científica, o que significa que resultados de pesquisas científicas devem ser comunicados entre os pares e também divulgados para a mídia e ao público em geral (OLIVEIRA, 2001).

Nas universidades, porém, a produção científica ainda não é socializada de maneira satisfatória e a maior parcela do conhecimento gerado nessas instituições permanece na invisibilidade (QUEIROZ; BECKER, 2016; CARMO, 2015; BUENO, 2014). Na Universidade Federal de Goiás (UFG), documentos institucionais como Estatuto, Plano de Desenvolvimento Institucional (PDI) e Regimento Geral apontam e orientam no sentido de que a produção científica da Instituição seja compartilhada e alcance a sociedade. Mas, na prática cotidiana da Universidade, essas iniciativas mostram-se fragmentadas, dispersas e de difícil acesso à população em geral.

Assim, neste trabalho buscou-se responder ao seguinte questionamento: Como a UFG pode aumentar a visibilidade da sua produção científica, ampliando a socialização dos conhecimentos gerados por ela?

Para responder a esta pergunta, primeiramente, esta pesquisa procurou compreender como a UFG faz a difusão de sua produção científica, para depois propor um Modelo de Portal para a Ciência a ser utilizado pela Instituição no sentido de impulsionar seu trabalho de comunicação e divulgação de ciência.

Para alcançar tais objetivos foram identificados a forma de inserção da socialização de conhecimentos nos documentos institucionais da UFG; os instrumentos de comunicação e divulgação científica empregados na Instituição; as lacunas existentes nos processos de circulação de informações científicas na Universidade, para os públicos internos e a sociedade em geral; e, finalmente, foram relacionados parâmetros, requisitos e diretrizes para elaboração de um Modelo de Portal para difusão da produção científica da UFG.

\section{DIÁLOGOS ENTRE CIÊNCIA E SOCIEDADE}

A difusão científica, entendida como um termo genérico, ou seja, como "todo e qualquer processo ou recurso utilizado na veiculação de informações científicas e tecnológicas" (CARIBÉ, 2015, p. 93), garante benefícios a própria ciência, aos indivíduos e aos países. A ciência ganha com a possibilidade de maior associação entre cientistas e instituiç̃oes e aumento da credibilidade e do apoio da sociedade. Os indivíduos, ao agregar informações sobre as descobertas científicas ao seu dia a dia, podem tomar decisões pessoais de maneira mais consciente, têm oportunidade de satisfazer curiosidades naturais e de formar uma cultura científica. As nações se beneficiam porque há um estímulo às carreiras tecnocientíficas e à formação de trabalhadores mais especializados, garantido competitividade aos paises e pleno funcionamento da democracia (PEREIRA, 2012; CASTELFRANCHI, 2008; MUELLER, 1995).

Como no Brasil as universidades públicas recebem o maior percentual dos recursos direcionados à C\&T e são responsáveis pela maior produção científica do País, também a estas instituições cabe o importante papel de divulgar ciência, prestar contas à sociedade, garantir a formação de mão de obra qualificada e, em última instância, auxiliar na formação de uma cultura científica. 
No que se refere a recursos, em 2012, a pesquisa em instituições de ensino superior ficou com 61\% do total gasto pelo governo em P\&D (UNESCO, 2015). O CNPq, por exemplo, no ano de 2008 direcionou US\$195 milhões para projetos de pesquisa, sendo que $64 \%$ desse valor teve como destino universidades federais de todo o País e mais três instituições estaduais paulistas: USP, UNESP e UNICAMP (CHIARINI; VIEIRA, 2012).

Em relação à produção científica brasileira, Santos (2015) aponta que perto de $90 \%$ estava vinculada às universidades no período de $2003 / 2012$, sendo que entre as 20 instituições mais produtivas todas eram públicas, 14 federais e 6 estaduais.

Mas, independe do tipo de instituição na qual a pesquisa científica esteja sendo desenvolvida, é preciso mais do que o envolvimento individual dos cientistas nos processos de difusão científica. Para Candotti (2002, p. 18), cabe muito mais às instituições produtoras de pesquisa científica a tarefa de criar e impulsionar ações para socialização de conhecimentos científicos porque a responsabilidade final pelos resultados e pelas aplicações de toda produção científica é atribuída às instituições e "deixar essa responsabilidade aos indivíduos, mesmo que cientistas respeitáveis, seria abandonar a possibilidade de preservar, entre nossos ideais, o de construir um mundo mais justo e igualitário".

\subsection{Entraves à divulgação científica}

Os entraves a edificação de práticas de divulgação científica de qualidade e eficazes no Brasil são muitos e incluem desde a falta de visão dos dirigentes das instituições de C\&T até a formação inadequada de divulgadores, o pouco interesse de cientistas/pesquisadores, a baixa formação educacional básica da população em geral, a diversidade cultural dos públicos, o pouco compromisso social dos centros produtores de conhecimento científico, e o restrito papel educativo atribuído à divulgação científica (BUENO, 2009a).

Embora a pesquisa científica desenvolvida no Brasil esteja, cada vez mais, sendo socializada com a população em geral, parte significativa dos pesquisadores ainda temem "construir pontes com públicos não especializados" e até mesmo com seus pares (CARVALHO; CABECINHAS, 2004, p. 6). No que diz respeito à divulgação de ciência nos meios de comunicação de massa, essas autoras dizem que os principais medos dos cientistas são o sensacionalismo, a simplificação exagerada ou interpretações equivocadas que possam comprometer o entendimento completo dos resultados das pesquisas.

Bueno (2009a) acrescenta que também é empecilho à mais ampla divulgação de ciência o fato de muitas instituições nacionais produtoras de conhecimento não fomentarem uma cultura de comunicação voltada para a necessidade de disseminar informações científicas a públicos diversos, inclusive ao cidadão comum. Para explicar a ausência dessa cultura de comunicação científica, esse autor salienta que dirigentes de muitos centros de pesquisa ainda não veem a divulgação científica como estratégica.

Sobre essa discussão, Duarte (2004) diz que o compromisso com a democratização da informação científica precisa ser de todo o corpo constituinte de uma instituição produtora de ciência: pesquisadores, gestores, comunicadores. Por isso, esse autor vê como fundamental que essas instituições disponham de sistemas de difusão da ciência acessíveis a todos os públicos e que dirigentes e pesquisadores sejam capacitados para que tenham "autossuficiência comunicativa" e assumam postura ativa nos processos de socialização do conhecimento.

Para impulsionar essa prática de educação para a ciência no interior das instituições públicas de ciência, Duarte (2004) aponta algumas alternativas. Uma das propostas é que atividades de transmissão dos resultados obtidos sejam incorporadas a cada projeto de pesquisa, sendo essas ações de socialização integradas aos sistemas de avaliação. Outras possibilidades são a realização de discussões internas para conscientização, mobilização e estímulo à divulgação científica, preparação de manuais orientadores e capacitações para que pesquisadores e todos da instituição estejam preparados para fazer interação com os meios de comunicação e outras mídias.

\subsection{Qual divulgação científica?}

A divulgação de temas relacionados à ciência, de resultados de pesquisas científicas, na perspectiva de apenas informar a sociedade sobre os avanços científicos e tecnológicos, sem oferecer possibilidade de diálogo 
e debate em relação aos riscos e incertezas das aplicações científicas e tecnológicas não é mais possível (CALDAS, 2010). Segundo essa autora, na divulgação científica não se deve renunciar ou negar as especificidades e complexidades inerentes à produção científica, mas, por outro lado, os conhecimentos produzidos não podem ser apartados da realidade em que foram desenvolvidos porque o contexto cultural, histórico, político e econômico estão relacionados ao fazer científico.

Bortoliero (2011, p. 1) expressa essas mesmas preocupações e ressalta que a pesquisa científica e tecnológica pode estar vinculada a variados interesses porque "os cientistas, os pesquisadores defendem posições, submetem-se a patrocínios, mantêm relações de afinidade com partidos políticos, correntes ideológicas etc".

Tendo em vista esses posicionamentos, é coerente a recomendação apresentada por Bueno (200gb, p. 122) de que no jornalismo científico os profissionais devem manter postura crítica e evitar "[...] deslumbramento em relação às novas descobertas, ignorando os interesses subjacentes à produção científica e tecnológica", pois os avanços da ciência podem ser traduzidos em processos tecnológicos de grande valor comercial, mas que não necessariamente serão benéficos à sociedade.

Dunwoody (2014) faz a ressalva de que o jornalismo científico precisa ser um espaço de credibilidade porque quando praticado de maneira precária pode levar à comercialização da ciência. A autora explica que não é incomum empresas e anunciantes gerarem desinformação para impulsionar a venda de produtos, problema que pode ser acentuado com a omissão ou mesmo a participação de jornalistas/divulgadores e instituições que fazem pesquisa.

Um outro aspecto que Duarte (2004) incorpora à discussão sobre como fazer divulgação científica é a necessidade de instituições de pesquisa e cientistas buscarem novos mecanismos de interlocução com a sociedade. Para esse autor, conteúdos de ciência apenas nos veículos tradicionais de comunicação de massa servem mais como distração e não asseguram educação, interação e compartilhamento de conhecimentos com a população leiga.

Para Bortoliero (2011) e Vogt (2003) os objetivos da divulgação científica devem estar direcionados à formação de uma cultura científica, pois, para eles, a ciência é uma construção humana e cultural que para ser inserida na cultura de uma sociedade requer o envolvimento de amplos setores: cientistas, instituições que financiam e produzem ciência; professores e alunos envolvidos na aprendizagem de ciências; governos que promovem políticas públicas direcionadas à ciência e tecnologia; sistemas de comunicação eficientes e capazes de promover uma divulgação científica a diferentes audiências, seja por meio de museus, planetários, reservas ambientais, nos meios de comunicação de massa ou em mídias alternativas.

\subsection{Interesse do brasileiro por ciência}

Pesquisas de opinião pública realizadas no Brasil desde 1987 - no total foram 4 levantamentos, 1987, 2006, 2010 e 2015 - indicam que o brasileiro tem interesse e confiança no trabalho desenvolvido pelos cientistas. $\mathrm{Na}$ enquete de 2015 sobre a percepção pública da C\&T, os entrevistados que apontaram que a ciência e a tecnologia trazem mais benefícios do que malefícios para a humanidade foi de $73 \%$ e os que demonstraram interesse pela temática foram $86 \%$ - somados os muito interessados, interessados e pouco interessados. Nos levantamentos anteriores, o percentual de interessados em C\&T também foi maioria - 85\%, em 2010; $76 \%$, em 2006; e 71\%, em 1987 (CGEE, 2015; BRASIL, 2010, 2006, 1987).

A última pesquisa (CGEE, 2015) demonstrou ainda que os entrevistados acreditam que as desigualdades sociais no Brasil podem ser reduzidas se houver mais desenvolvimento científico e tecnológico $34,9 \%$ disseram concordar totalmente com essa afirmativa e $17,2 \%$ concordaram parcialmente com essa afirmativa. Os brasileiros também querem ser consultados sobre os caminhos da ciência e tecnologia no País $46,9 \%$ disseram concordar totalmente com essa afirmativa e 36,8\% concordaram em parte.

E para os participantes dessa enquete de 2015 a maioria das pessoas pode compreender os saberes gerados pela ciência, se eles forem bem explicados (veja o Gráfico 1). 
Gráfico 1 - A maioria das pessoas é capaz de entender o conhecimento científico se ele for bem explicado?

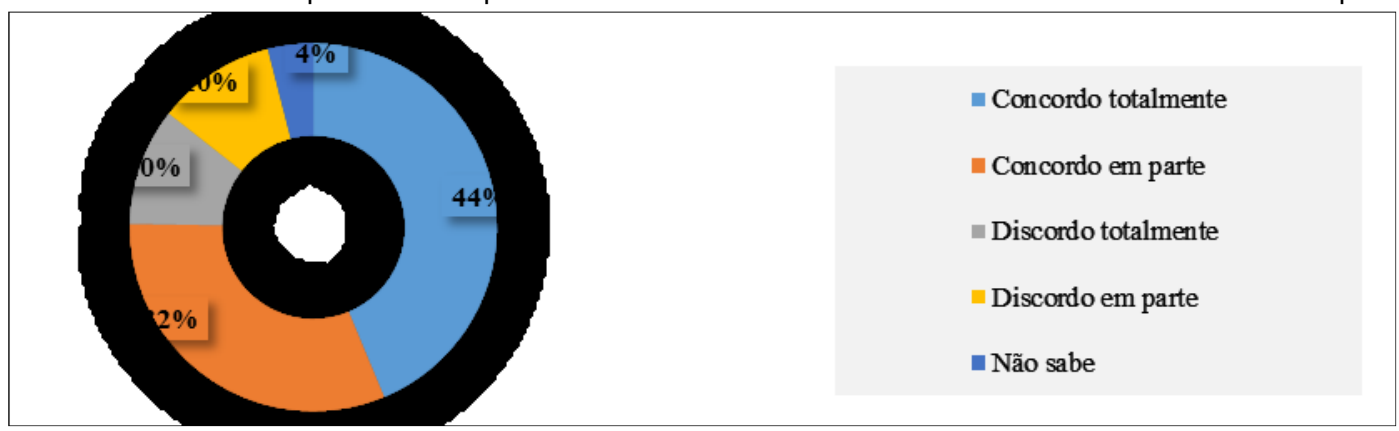

Fonte: Elaborado pelos autores a partir de CGEE (2015).

Mas, apesar desses dados positivos sobre interesse, confiança e desejo de participar das discussões sobre C\&T no País, os brasileiros ouvidos nas três últimas enquetes demonstraram saber pouco sobre a temática. Mais de $80 \%$ não conseguiram identificar alguma instituição dedicada à pesquisa científica no Brasil e mais de $90 \%$ não se lembraram do nome de algum cientista do País.

Para ter acesso a informações sobre C\&T o veículo mais utilizado pelos brasileiros, segundo a pesquisa de 2015 , é a TV, mesmo assim só $21 \%$ dos entrevistados disseram fazer isso com muita frequência. O meio que vem se consolidando como possibilidade para aquisição de informação científica é a internet. Entre os levantamentos realizados de 2006 a 2015 as pessoas que disseram buscar conhecimento científico e tecnológico na rede mundial de computadores saltaram de 23\%, em 2006, para 48,7\%, em 2015 - somados os que acessavam com pouca ou muita frequência, conforme pode ser visto no Gráfico 2.

Gráfico 2 - Quanto o brasileiro acessa informação sobre ciência tecnologia pela Internet e redes sociais, 2015, 2010 e 2006

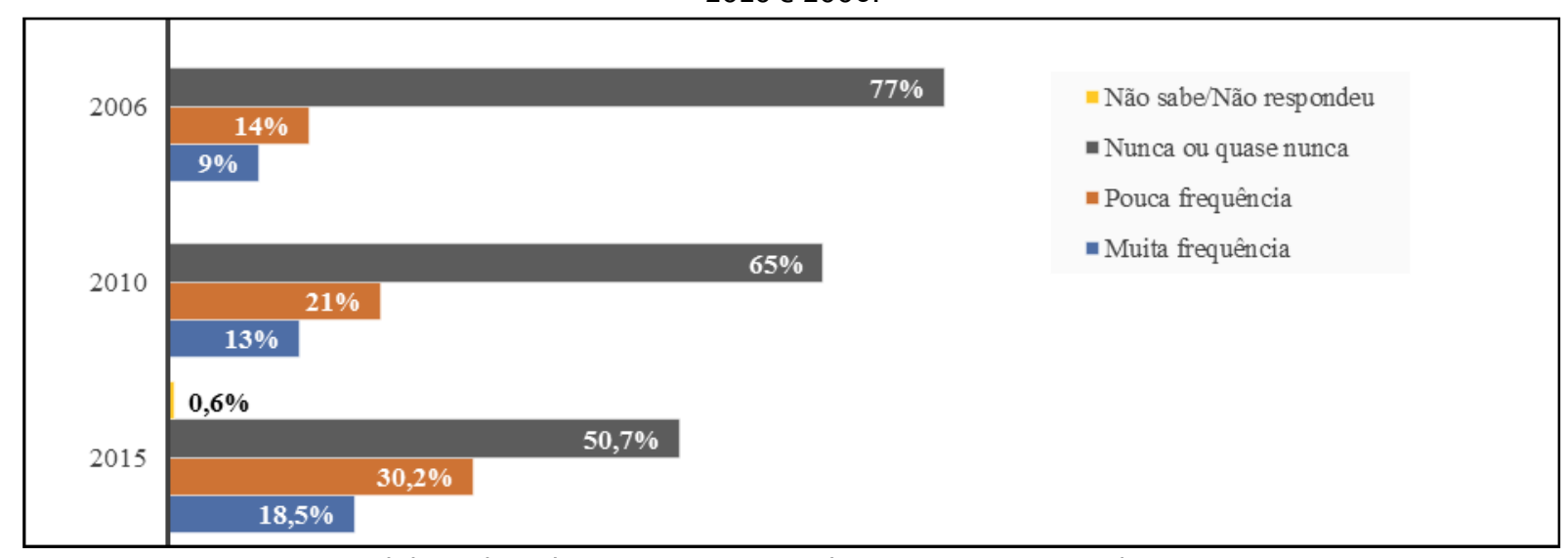

Fonte: Elaborado pelos autores a partir de CGEE (2015); Brasil (2010, 2006).

Quanto à satisfação com a qualidade das informações sobre C\&T noticiadas pelos meios de comunicação, o maior percentual declarado, na pesquisa de 2015 , foi para a internet (55\%), seguido pela TV (49\%) e jornais impressos (40\%). Os motivos de insatisfação citados foram, principalmente, o número insuficiente de matérias, fontes pouco confiáveis e conteúdo de má qualidade (CGEE, 2015; BRASIL, 2010; 2006; 1987).

Segundo a pesquisa de 2015 , os canais mais consultados na internet para obtenção de informações sobre C\&T foram os sítios de instituições de pesquisa (42,4\%), seguidos de sítios de jornais e revistas (39,5\%), Facebook (28,1\%), Wikipedia (14,3\%), blogs (14\%), Google (4,3\%), Twitter (2,9\%) e Youtube (0,4\%). E na busca por informações sobre C\&T na internet os jovens são os principais atores. Somando os que disseram fazer isso com 
muita ou pouca frequência o percentual chega a 68\%, na faixa etária de 16 a 17 anos, e a 74,1\%, entre aqueles de 18 a 24 anos (CGEE, 2015).

\subsection{Difusão científica e internet}

Vistas essas nuances sobre o interesse, mas ao mesmo tempo a pouca informação que os brasileiros têm da temática científico-tecnológica, e analisando os resultados da última pesquisa sobre percepção pública da C\&T, que indicam serem os jovens os mais interessados e a internet o meio preferido desse público na busca por informações sobre C\&T, os novos sistemas de comunicação e informação criados a partir da rede mundial de computadores têm se apresentado como os aliados mais interessantes e promissores para ampliação da difusão científica.

Segundo Peters et al (2014, tradução dos autores), público diverso e expressivo para a ciência estão conectados à rede mundial de computadores, sendo assim, comunicadores e divulgadores de ciência precisam se esforçar para encontrá-los nesta nova mídia. Estes autores ainda acrescentam que nas plataformas on line, que oferecem novos canais e formatos para circulação da informação científica, as oportunidades de diálogo com os públicos se ampliam e, por isso, podem "transformar fundamentalmente a interface entre ciência e sociedade".

Com a utilização da internet, cientistas de diferentes locais e áreas do conhecimento podem desenvolver trabalhos em conjunto, à distância, podendo, desta maneira solucionar problemas complexos em menos tempo, com gasto financeiro também menor. Além disso, com a internet os resultados das pesquisas científicas chegam a mais pessoas, em menos tempo e com um custo muito menor, alcançando seu sentido de universalidade (PINHEIRO, 2012; VALERIO; PINHEIRO, 2008).

Valerio (2012, p. 152) concorda com essa visão e classifica o advento da utilização da web como "[...] um salto paradigmático para a informação e a comunicação [científica], especialmente no que se refere ao acesso", ressaltando ainda que a disseminação de informações em redes eletrônicas não ocorre de maneira linear, em mão única, mas permite que os indivíduos sejam ao mesmo tempo consumidores e produtores, emissores e receptores de mensagens.

A internet como mecanismo para compartilhamento de conteúdo sobre ciência oferece vários formatos: portais, sítios, blogs, redes sociais - com seus muitos recursos multimídia, áudio, vídeos, fotos etc (SPINA, 2016; PEREIRA, 2014). Entretanto, qualquer tentativa de apontar os recursos mais adequados para a divulgação e comunicação científica na rede mundial de computadores pode ficar ultrapassada em pouco tempo, pois as ferramentas tecnológicas se alteram com grande velocidade (PEREIRA, 2014).

Ao estudar as estratégias de divulgação científica implementadas pelo Projeto AlcScens (Grupo de Pesquisa em Mudanças Climáticas da Unicamp), Pereira (2014) concluiu, por exemplo, que o uso de redes sociais para divulgação científica é muito interessante pela quantidade e diversidade de públicos que as utilizam rotineiramente, mas, por outro lado, por serem atualizadas constantemente impedem o armazenamento de informações, uma vez que rapidamente uma informação é sobreposta por outra.

Assim, a estruturação de sítios ou portais, aliados a outras ferramentas digitais, têm sido as alternativas utilizadas na busca por ampliar os canais para socialização da produção científica de centros, universidades e instituições de pesquisa. A partir da definição apresentada por Santos (2016, p. 1) de que portal é "[...] uma página específica na internet, que serve como ponto de acesso direto a outros conjuntos de serviços e informações, contendo subdivisões específicas sobre determinado tema ou área do conhecimento", Rodrigues e Fachin (2010) dizem que a criação de portais na internet contribui para ampliar a visibilidade e o valor público das instituições científicas.

No Brasil, o projeto considerado pioneiro para divulgação científica na internet é o Portal CanalCiência (www.canalciencia.ibict.br), lançado em 2002 pelo IBICT -Instituto Brasileiro de Informação em Ciência e Tecnologia -, unidade de pesquisa do MCTIC - Ministério da Ciência, tecnologia, Inovações e Comunicações (IBICT, 2017; PINHEIRO; SILVA, 2007). 
Nas universidades brasileiras os primeiros projetos on line direcionados a ampliar a circulação dos resultados de pesquisas científicas estiveram relacionados à chamada comunicação científica, ou seja, entre os pares, com a estruturação de revistas científicas eletrônicas e portais na internet para publicação desses periódicos (BOMFÁ; CASTRO, 2004).

Processos de difusão científica que englobem também a população em geral são mais recentes nas universidades e, segundo alguns autores, ainda têm dificuldade de cumprir a função de mostrar à sociedade a produção de ciência realizada nas IES (QUEIROZ; BECKER, 2016; CARMO, 2015; BUENO, 2014).

Na Espanha, as universidades públicas já compreenderam a relevância que a internet tem como veículo para difusão da ciência e, por isso, segundo estudo realizado por López-Pérez e Olvera-Lobo (2016), cerca de $70 \%$ delas possuem em seus sítios institucionais um canal específico para divulgação de ciência. Mas, para estas autoras, não basta as universidades e centros de ciência criarem canais de divulgação de ciência, é preciso tornálos visíveis e, quando possível, unificar projetos para uma melhor gestão da informação científica que chega ao público em geral e também para se criar ambientes confiáveis para pesquisas jornalísticas, por exemplo.

No Brasil, estudo realizado por Bueno (2014) com a análise dos portais institucionais de quatro universidades: Estadual de Londrina (UEL); Federal de Santa Catarina (UFSC); Tuiuti do Paraná (UTP) e Pontifícia Universidade Católica do Rio Grande do Sul (PUCRS), concluiu que os vários públicos de interesse têm dificuldade em medir e acompanhar os investimentos e os resultados do trabalho realizado pelos pesquisadores dessas instituições porque as atividades realizadas, quase sempre, são de difícil visualização. No Quadro 1, a seguir, estão resumidos alguns dos problemas identificados no levantamento.

Quadro 1 - Principais problemas de divulgação científica nos portais da UEL; UFSC; UTP e PUCRS.

\section{Problemas}

- Inexistência ou pouca articulação entre os responsáveis pelos portais e os órgãos de pesquisa;

- Informações sobre atividades de pesquisa não estavam à disposição para publicação;

- Divulgação científica não faz parte da cultura de algumas instituições;

- Democratização do conhecimento não estava entre as funções mais importantes das instituições;

- Dados de projetos de pesquisa são insuficientes e até inexistentes nos portais institucionais.

Fonte: Elaborado pelos autores a partir de Bueno (2014).

Carmo (2015) também estudou os processos de divulgação científica empreendidos em universidades. O trabalho da autora foi realizado em abril de 2015 nos portais de três instituições universitárias do Grande $A B C$, no Estado de São Paulo: Metodista de São Paulo (UMESP); Universidade Municipal de São Caetano do Sul, (USCS); e Federal do ABC (UFABC).

Partindo da análise de critérios como estrutura da página inicial dos portais, informações sobre pesquisas, localização do repositório de teses e dissertações e linguagem empregada na divulgação de pesquisas científicas, a autora identificou alguns problemas e traçou propostas de melhoria para os processos de divulgação científica das universidades pesquisadas (Quadro 2).

Quadro 2 - Resumo dos principais problemas e propostas de otimização dos fluxos de informação científica nas universidades do Grande ABC.

\section{Diagnóstico Propostas}

- Existiam diretrizes organizacionais no sentido • Um ambiente específico para divulgação científica precisa de valorização da divulgação científica nas três instituições, mas nenhuma apresentava fluxo de comunicação nesse sentido;

- UFABC e UMESP já haviam iniciado a ser formalizado de maneira que seja possível criar uma referência da atividade nas Universidades e também para que alguns profissionais dediquem horas de trabalho para esse fim, com olhar voltado à pesquisa científica; formalização de espaço dedicado à divulgação científica. Na USCS não se identificou perspectiva nesse sentido, mas a instituição desenvolvia ações de divulgação de sua produção científica;

- Um fluxo de comunicação para divulgação científica deve ser instituído nas três Universidades para que consigam desenvolver, formalizar, distribuir funções e terem metas e resultados com a circulação do conhecimento gerado internamente; 
- Os sites institucionais se apresentavam como uma das principais ferramentas de comunicação das Universidades e também como instrumentos para divulgação científica, mas nas análises empreendidas constatou-se grande dificuldade para encontrar informações dessa temática. Apenas no site da UMESP o link Divulgação Científica é encontrado na página inicial;

- Além dos sites, também se mostraram subutilizados para a divulgação científica as TVs e Rádios das Universidades;

- Teses e dissertações produzidas nas Universidades seguiam para os repositórios e, a maioria delas, permanecia lá, sem nunca ser divulgada.
- Autores de teses ou dissertações, na entrega do trabalho final, devem apresentar um pequeno release para divulgação científica. Esse release ganharia espaço no site da instituição, redes sociais, e iria à Assessoria de Comunicação e também à Pró-Reitoria de Extensão; - O profissional de comunicação precisa integrar as ações de divulgação científica pelo conhecimento que dispõe sobre os processos comunicacionais;

- O ambiente específico para divulgação científica e os profissionais responsáveis por administrar o fluxo de conteúdos podem estar alocados no setor de comunicação, pesquisa, extensão ou em um núcleo formado por todas essas partes. O fundamental é que a pesquisa científica das universidades seja percebida e divulgada.

Fonte: Elaborado pelos autores a partir de Carmo (2015).

Também em busca de identificar instituições de ensino superior que possuem trabalho estruturado de divulgação e/ou jornalismo científico Queiroz e Becker (2016) analisaram as 50 primeiras universidades brasileiras, segundo o Ranking Universitário Folha - RUF 2015. A pesquisa nos sítios dessas instituições constatou que a divulgação científica é uma preocupação relevante em apenas 15, sendo 14 delas públicas. Os critérios levados em conta no estudo foram navegabilidade, se simples e intuitiva; se apresentava como ponto central temáticas relacionadas à C\&T, principalmente geradas na própria instituição; atualização das notícias; linguagem e apresentação das notícias direcionadas ao leitor comum. Entre os diferenciais positivos encontrados nos cinco melhores sítios de divulgação científica das universidades estavam boas ferramentas/plataformas de busca e de interação com os públicos, sobretudo com estudantes e com a imprensa.

\section{METODOLOGIA}

Este estudo identifica-se como sendo de natureza aplicada, com abordagem qualitativa do problema e coleta de dados realizada em ambiente natural. Do ponto de vista de objetivos, o caráter da pesquisa foi descritivo-exploratório, tratando-se também de uma pesquisa-ação, pois os pesquisadores integram a instituição pesquisada e o resultado do estudo vai de encontro à necessidade apontada pela própria instituição.

No que diz respeito aos procedimentos técnicos, neste trabalho a escolha foi pela utilização da pesquisa bibliográfica e documental. Na pesquisa bibliográfica buscou-se conhecer a realidade da difusão científica no Brasil e colher indicativos de requisitos, parâmetros e diretrizes para construção de um modelo de portal para a ciência que contribua para ampliar a circulação de informações científicas.

Na pesquisa documental, realizada em fontes primárias, foram analisados documentos institucionais da UFG, o Portal UFG e os sítios oficiais de estruturas centrais da UFG. A coleta de dados nas fontes primárias ocorreu entre os meses de setembro e outubro de 2017. O objetivo foi localizar diretrizes em favor da difusão científica nos documentos institucionais da UFG; iniciativas para socialização de conhecimentos científicos nos sítios das estruturas centrais da Universidade; como ocorre a circulação de informações científicas a partir das estruturas oficiais de comunicação da UFG e, a partir dos dados obtidos nos questionamentos anteriores, descrever as iniciativas mais importantes desenvolvidas na UFG para transmissão à sociedade dos resultados de estudos científicos da Universidade.

A reunião dos elementos identificados permitiu a elaboração de um retrato de como a UFG promove comunicação e divulgação de ciência: as boas iniciativas; as lacunas e necessidades existentes.

Com a coleta de dados realizada em várias fontes de evidências, o propósito foi abranger a máxima amplitude na descrição, na explicação e na compreensão do objeto em estudo, como propõe Oliveira (2011). E, partindo da premissa sugerida por Triviños (1987) de que na pesquisa qualitativa não há uma separação clara entre a coleta de informações e a sua interpretação, principalmente se o pesquisador estiver inserido no ambiente pesquisado. Neste trabalho, a análise dos dados foi desenvolvida durante toda a investigação. 
Para esse trabalho seguiu-se esquema proposto por Minayo (2014), segundo o qual a fase de análise de dados apresenta três objetivos: compreender os dados coletados, confirmando ou não o que a pesquisa previa e/ou respondendo às perguntas realizadas; aumentar as informações a respeito da temática em estudo; e articular essas novas informações ao contexto cultural em que estão inseridos.

\section{SOCIALIZAÇÃO DE CONHECIMENTOS CIENTÍFICOS NA UFG}

A UFG tem como concepção que seus papéis fundamentais são produzir e compartilhar conhecimentos, ou seja, realizar pesquisas e difundir os resultados desses estudos, não apenas internamente ou entre outras instituições produtoras de conhecimento, mas à população em geral (UFG, 2017a).

Para identificar de que forma a Instituição coloca em prática diretrizes nesse sentido, esta pesquisa analisou documentos e sítios da Universidade para, em seguida, propor um Modelo de Portal na internet que possa auxiliar a UFG a alcançar seus objetivos de difundir ciência.

\subsection{Diagnóstico}

Nos documentos institucionais da UFG analisados nesta pesquisa a preocupação da Universidade com a socialização de conhecimentos gerados internamente fica explícita em vários momentos.

No Quadro 3 estão resumidas as principais referências identificadas.

Quadro 3 - Difusão científica nos documentos institucionais da UFG.

\section{Estatuto UFG/2013}

- Princípios da UFG: [...] universalidade do conhecimento; socialização de seus benefícios;

- Finalidades da UFG: [...] transmitir, sistematizar e produzir conhecimentos [...].

\section{Carta de Serviços ao Cidadão UFG/2012}

- Sobre a comunicação da UFG: O processo comunicativo deve assentar-se na fluência e na influência de suas informações, contribuindo para a socialização do conhecimento produzido pela Universidade; Trata-se, pois, de garantir, de maneira eficiente, dois componentes indispensáveis a uma universidade cidadã: direito à informação e socialização do conhecimento.

\section{PDI 2011-2017)}

- $\quad$ A UFG é [...] caracterizada como espaço plural de produção e socialização do conhecimento; ao executar sua política de graduação, a UFG deve desenvolver ações que: auxiliem os órgãos suplementares da UFG em suas atividades de ensino e socialização de conhecimentos;

- Política de Pesquisa, Pós-Graduação e Inovação: ao executar sua política de pesquisa, pós-graduação e inovação, a UFG deve desenvolver ações que favoreçam sistematicamente a publicação de artigos e outros meios de divulgação de produtos, estudos e pesquisas desenvolvidos; divulguem as atividades desenvolvidas pelos programas de pós-graduação utilizando as diferentes mídias (internet, folders, cartazes, Jornal da Universidade, Rádio Universitária, TV UFG); consolidem o projeto de divulgação por meio eletrônico das revistas da universidade, bem como das teses e dissertações dos programas de pós-graduação.

\section{Regimento Geral da UFG/2015}

- Art. 121. Os programas de Pós-Graduação stricto sensu terão por objetivo a produção e a difusão do conhecimento [...];

- $\quad$ Art. 137. A extensão terá como objetivo promover a interação dos saberes entre a Universidade e a Sociedade, procurando, por meio de um processo educativo, cultural e científico, socializar o conhecimento acadêmico [...].

$$
\text { Plano de Gestão 2014-2017 }
$$

- Garantir apoio aos pesquisadores em todas as etapas da produção do conhecimento, passando pela elaboração dos projetos, execução das atividades, prestação de contas até a apropriação do conhecimento pela sociedade;

- Estimular todas as formas de divulgação dos produtos científicos, tecnológicos e artísticos, especialmente via programa Viver Ciência da TV-UFG; 
- O processo comunicativo deve ter como base a fluência e a influência de suas informações, contribuindo para a socialização do conhecimento produzido na Universidade.

$$
\text { PDTI 2014- } 2015
$$

- Consolidar os periódicos científicos da UFG por meio da consolidação do Sistema de Editoração Eletrônica das Revistas;

- Reforçar a comunicação interna na UFG por meio da sistematização de um banco de dados de especialistas da UFG em cada área de conhecimento;

- Necessidades Identificadas: dar visibilidade e promover a preservação digital da produção científica.

$$
\text { PDI 2018-2022 }
$$

- Missão: A UFG tem como missão produzir, sistematizar e socializar conhecimentos e saberes, formando profissionais e cidadãos comprometidos com o desenvolvimento da sociedade;

- $\quad$ A UFG [...] tem por finalidade produzir, sistematizar e transmitir conhecimentos [...];

- A pós-graduação stricto sensu da UFG tem por objetivo [...] a produção do conhecimento e a sua difusão por meio de redes de colaboração científica em diferentes áreas do conhecimento;

- Criar um portal multimídia de divulgação científica.

\section{Resolução - CONSUNI No 18/2017}

- Sobre normas para avaliação, progressão e promoção que determinam novas atividades para pontuação no RADOC (Relatório Anual do Docente):

- Pontuação pela criação e manutenção de páginas em Redes sociais, websites e blogs, pela participação em entrevista, mesa redonda, comentário ou programa de rádio, TV, impressos e mídia digital; pela publicação de artigos de opinião veiculados em jornais e revistas (eletrônico ou impresso), texto ou material didático para uso institucional, e artigos de divulgação científica, tecnológica e artística veiculados em jornais e revistas (eletrônico ou impresso).

Fonte: Elaborado pelos autores a partir de UFG (2017a; 2017b, 2015a, 2015b, 2014a, 2014b, 2014c, 2012).

Nos sítios das estruturas centrais da UFG: Regionais; Pró-Reitorias; e Órgãos, nem sempre foi possível encontrar ambientes, diretrizes, iniciativas ou informações sobre ciência, projetos e núcleos de pesquisa, teses e dissertações defendidas na Universidade. Entre as quatro Regionais da UFG foi possível localizar a presença de difusão científica nos sítios das Regionais Catalão e Jataí. Para a Regional Goiânia não foi localizado sítio específico e no sítio da Regional Goiás não foram localizadas ações de difusão científica no período pesquisado.

Nos sítios das Pró-Reitorias da UFG iniciativas visando difusão científica ou diretrizes nesse sentido foram encontradas em quatro delas: de Graduação, Pós-Graduação, Pesquisa e Inovação e de Extensão e Cultura. Já entre os 18 órgãos da UFG que integraram a pesquisa, foi identificada difusão científica em metade deles.

De maneira geral, o levantamento de dados nos sítios das estruturas centrais da UFG mostrou que uma parte significativa delas promove algum tipo de difusão científica ou apresenta diretriz nesse sentido. Entretanto, as iniciativas existentes estão pouco visíveis e a maioria não ocorre de maneira sistemática, em ambientes específicos.

No que diz respeito a informações sobre projetos e núcleos de pesquisa ou teses e dissertações defendidas na UFG a visibilidade é ainda menor. De todos os sítios pesquisados: de três Regionais; sete PróReitorias; e 18 órgãos da Universidade, em apenas três havia algum tipo de informação ou link para esses setores.

Por serem estruturas centrais da UFG e seus sítios representarem o canal de interação mais visível e acessível a maior parcela da sociedade, pode-se dizer que, embora informações sobre a produção científica da UFG estejam circulando, elas ganham muito pouca amplitude.

Os dados obtidos nos sítios das três estruturas oficiais de comunicação da UFG: Assessoria de Comunicação (Ascom); Rádio Universitária; e TV UFG, demonstram que a Ascom é o veículo que mantém o maior número de canais de interação entre a Universidade - no período pesquisado eram 10 - e seus públicos. $E$ a quase totalidade desses canais divulgam conteúdos voltados à socialização do conhecimento científico gerado na UFG. A interlocução, de maneira geral, se dá com a comunidade da UFG, a sociedade em geral e visando o público leigo. 
A Rádio Universitária da UFG não apresenta nenhum programa específico no qual a UFG possa falar com seus públicos, internos ou externos, com exceção do Boletim Informativo - de aproximadamente cinco minutos - produzido pela Ascom e veiculado na emissora como parte de um programa jornalístico.

Pela descrição encontrada no sítio da TV UFG sobre as cinco produções próprias da emissora pode-se dizer que elas buscam promover interação entre a Universidade e a sociedade em geral, sendo que um desses programas (Viver Ciência) está totalmente voltado à divulgação dos conhecimentos científicos produzidos na UFG e outro (Se Liga na UFG!) insere conteúdos sobre a pesquisa científica nas discussões que promove. Desta maneira, a TV UFG coloca em prática sua diretriz de difundir conhecimentos científicos, principalmente os gerados na UFG, apresentada em sua missão, visão e valores.

Levando-se em conta os canais de interação da UFG com seus públicos, vinculados às estruturas oficiais de comunicação da Universidade, pode-se dizer que informações sobre a produção científica da UFG estão circulando, dentro e fora da universidade, para públicos leigos e de especialistas. Entretanto, nota-se também que a transmissão dessas informações ocorre sem uma coordenação, ou seja, são iniciativas isoladas, dispersas, fragmentadas e pouco sistematizadas.

Das muitas iniciativas da UFG para socialização dos conhecimentos científicos produzidos na Instituição pode-se extrair 10 como sendo as mais importantes pelas características que apresentam, pela amplitude que alcançam e pelo potencial que representam para a circulação de informações científicas entre os públicos internos e externos à Universidade, leigo e especialista.

Para conhecer melhor os objetivos, canais que utilizam e os públicos pretendidos por essas iniciativas, cada uma delas foi estudada de maneira mais pormenorizada a partir de informações disponíveis em seus sítios.

Essa observação demonstrou que, em alguma medida, existe interação entre produtores e divulgadores de ciência e que os produtos/atividades apresentados conversam com públicos diversos: internos, externos, leigo e especialista. Os canais utilizados também são variados, mas há uma predominância dos meios digitais, às vezes como forma principal, algumas vezes de maneira complementar. Entretanto, por serem disponibilizadas de maneira fragmentada e dispersa podem não estar proporcionando à Universidade a amplitude de divulgação possível.

No Quadro 4 estão resumidas as principais características das iniciativas identificadas como mais importantes para socialização da produção científica desenvolvida na UFG.

Quadro 4 - Principais iniciativas para socialização do conhecimento científico na UFG.

\begin{tabular}{|c|c|c|c|c|}
\hline \multirow{2}{*}{$\begin{array}{c}\text { Iniciativa } \\
\text { (e estrutura à } \\
\text { qual está } \\
\text { vinculada) }\end{array}$} & \multirow[b]{2}{*}{ Objetivos } & \multirow[b]{2}{*}{ Canais que utiliza } & \multicolumn{2}{|c|}{ Públicos-alvo } \\
\hline & & & $\begin{array}{l}\text { Interno/ } \\
\text { externo } \\
\text { - ambos }\end{array}$ & $\begin{array}{l}\text { Leigo/ } \\
\text { Especialista - } \\
\text { ambos }\end{array}$ \\
\hline $\begin{array}{l}\text { Portal UFG } \\
\text { (Ascom) }\end{array}$ & $\begin{array}{c}\text { Divulgar pesquisas e assuntos relacionados } \\
\text { ao ensino, eventos, editais, serviços, } \\
\text { prêmios e convênios da Universidade. }\end{array}$ & $\begin{array}{l}\text { Portal UFG } \\
\text { www.ufg.br }\end{array}$ & Ambos & Ambos \\
\hline $\begin{array}{l}\text { Jornal UFG } \\
\text { (Ascom) }\end{array}$ & $\begin{array}{c}\text { Divulgar ações institucionais, serviços, } \\
\text { projetos de extensão e cultura, temas de } \\
\text { interesse social e os resultados de pesquisas } \\
\text { desenvolvidas na UFG. }\end{array}$ & $\begin{array}{c}\text { Sítio } \\
\text { https://jornalufgonlin } \\
\begin{array}{c}\text { e.ufg.br/i versão } \\
\text { impressa }\end{array} \\
\end{array}$ & Interno & Leigo \\
\hline $\begin{array}{l}\text { Projeto } \\
\text { Visibilidade } \\
\text { (Ascom) }\end{array}$ & $\begin{array}{l}\text { Fortalecer as ações de divulgação científica } \\
\text { realizadas pela Universidade. }\end{array}$ & 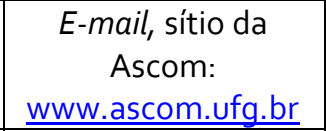 & Externo & Leigo \\
\hline $\begin{array}{l}\text { Museu de } \\
\text { Ciências } \\
\text { (PROEC) }\end{array}$ & $\begin{array}{c}\text { Ser espaço de socialização do } \\
\text { conhecimento por meio de uma rede } \\
\text { integrada de ações. Território de interação } \\
\text { entre a UFG e a sociedade. }\end{array}$ & $\begin{array}{l}\text { Sítio www.mc.ufg.br; } \\
\text { exposições; visitas. }\end{array}$ & Ambos & Leigo \\
\hline $\begin{array}{c}\text { Portal de } \\
\text { Periódicos } \\
\text { (PRPG e Sibi) }\end{array}$ & $\begin{array}{c}\text { Democratizar e promover o livre acesso às } \\
\text { produções científicas da UFG. }\end{array}$ & $\begin{array}{c}\text { Sítio } \\
\text { www.revistas.ufg.br } \\
\end{array}$ & Ambos & Especialista \\
\hline
\end{tabular}




\begin{tabular}{|c|c|c|c|c|}
\hline $\begin{array}{l}\text { Programa de } \\
\text { Formação em } \\
\text { Pesquisa (PRPI } \\
\text { e PRPG) }\end{array}$ & $\begin{array}{l}\text { Ampliar a difusão de ciência, da pesquisa } \\
\text { científica, e melhorar a capacidade da } \\
\text { comunidade acadêmica da UFG para } \\
\text { elaborar projetos de pesquisas, análise de } \\
\text { dados e divulgação cientifica. }\end{array}$ & $\begin{array}{l}\text { Palestras nas } \\
\text { Regionais da UFG; } \\
\text { transmissões pela } \\
\quad \text { internet }\end{array}$ & Interno & Ambos \\
\hline $\begin{array}{c}\text { Viver Ciência } \\
\text { (TV UFG e PRPI } \\
\text { e PRPG) }\end{array}$ & $\begin{array}{c}\text { Aproximar o conhecimento científico do dia } \\
\text { a dia das pessoas por meio de entrevistas } \\
\text { com pesquisadores sobre estudos } \\
\text { realizados na UFG, e o impacto destes na } \\
\text { sociedade. }\end{array}$ & TV UFG, Youtube, & Ambos & Leigo \\
\hline $\begin{array}{c}\text { Se Liga na UFG! } \\
\text { (TV UFG e } \\
\text { PROEC) }\end{array}$ & $\begin{array}{l}\text { Divulgar eventos e ações de ensino, } \\
\text { pesquisa e extensão da UFG. }\end{array}$ & $\begin{array}{l}\text { TV UFG, Youtube, } \\
\text { Facebook }\end{array}$ & Ambos & Leigo \\
\hline $\begin{array}{c}\text { Biblioteca } \\
\text { Digital de Teses } \\
\text { e Dissertações } \\
\text { - BDTD (PRPG } \\
\text { e Sibi) }\end{array}$ & $\begin{array}{l}\text { Reunir em um único portal de busca as } \\
\text { teses e dissertações defendidas por } \\
\text { brasileiros em instituições nacionais e } \\
\text { internacionais de ensino e pesquisa, } \\
\text { promovendo maior visibilidade da } \\
\text { produção científica nacional. }\end{array}$ & $\begin{array}{c}\text { Sítios } \\
\frac{\text { https://repositorio.bc }}{\text {.ufg.br/tede/ }} \\
\frac{\mathrm{e}}{\text { http://bdtd.ibict.br/v }} \\
\underline{\text { ufind/ }}\end{array}$ & Ambos & Especialista \\
\hline $\begin{array}{l}\text { Repositório } \\
\text { Institucional - } \\
\text { RI (Sibi) }\end{array}$ & $\begin{array}{l}\text { Preservar e facilitar o acesso a artigos } \\
\text { publicados em periódicos científicos, livros, } \\
\text { capítulos de livros, teses, dissertações, } \\
\text { trabalhos publicados em anais de eventos, } \\
\text { entre outras produções científicas da UFG. }\end{array}$ & $\frac{\text { https://repositorio.bc }}{\underline{\text { ufg.br/ }}}$ & Ambos & Especialista \\
\hline
\end{tabular}

Fonte: Elaborado pelos autores (2017).

A partir das sistematizações realizadas no referencial teórico deste estudo e da observação e análise dos elementos capturados na pesquisa documental e nos sítios das principais estruturas da UFG foi possível identificar como ocorre a difusão de ciência na Universidade, as boas práticas e as lacunas existentes, conforme resumo apresentado no Quadro 5, a seguir.

Quadro 5 - Difusão científica na UFG: desafios e lacunas.

\section{Desafios/Lacunas}

- A UFG não tem ambiente ou espaço específico para difusão científica; as ações, atividades e iniciativas para socialização dos conhecimentos gerados na UFG estão pulverizadas em vários sítios, programas e projetos;

- Muitas estruturas importantes da UFG não apresentam conteúdo ou direcionamento a ambientes que promovam difusão científica. A Instituição não tem uma cultura de difusão da ciência;

- Informações sobre projetos e núcleos de pesquisa existentes na UFG são de muito difícil acesso;

- Teses e dissertações defendidas na UFG não estão disponíveis em nenhuma das estruturas centrais da UFG de maneira direta;

- O acesso ao Portal de Periódicos da UFG só está visível nos menus dos sítios do Sibi, da TV UFG e no Portal UFG;

- A Rádio Universitária da UFG, embora tenha como Visão ser referência para popularização da ciência, não dispõe de programa específico voltado a essa temática; os temas de ciência divulgados na emissora estão pulverizados, sem um espaço definido; os conteúdos veiculados poderiam ganhar maior amplitude se fossem apresentados também a outros públicos, além dos ouvintes da emissora;

- Os conteúdos de divulgação científica produzidos e veiculados pela TV UFG podem ganhar maior amplitude se forem disponibilizados também em um ambiente próprio para difusão científica da UFG;

- Não há um banco de fontes, especialistas ou pesquisadores, acessível ao público interno ou externo à UFG; 
- O material de divulgação da produção científica da UFG produzido e veiculado pelos canais de comunicação da Ascom não estão acessíveis para consulta, seja para o público interno ou externo, de maneira simples e rápida;

- Os mecanismos de busca disponíveis nos sítios não estão integrados, são imprecisos e restritos;

- Conteúdos de divulgação científica disponíveis em muitos sítios são antigos e desatualizados;

- Necessidade de canal que permita articulação entre os setores que realizam pesquisas e todos os veículos de comunicação; ferramentas de interação entre pesquisadores e divulgadores e do público em geral com pesquisadores e divulgadores devem estar acessíveis para facilitar diálogos.

Fonte: Elaborado pelos autores (2017).

\subsection{Modelo de Portal para a Ciência}

Com base nas discussões apresentadas no referencial teórico, do diagnóstico traçado a partir dos documentos institucionais da UFG e da análise e observação dos sítios das principais estruturas da Universidade chegou-se aos elementos de referência para estruturação de um Modelo de Portal para difusão da produção científica da UFG.

Na Figura 1, a seguir, apresenta-se uma síntese dos parâmetros, diretrizes e requisitos identificados para estruturação de modelo de portal para a ciência em uma universidade:

Figura 1 - Elementos para concepção do Modelo de Portal para a Ciência da UFG.

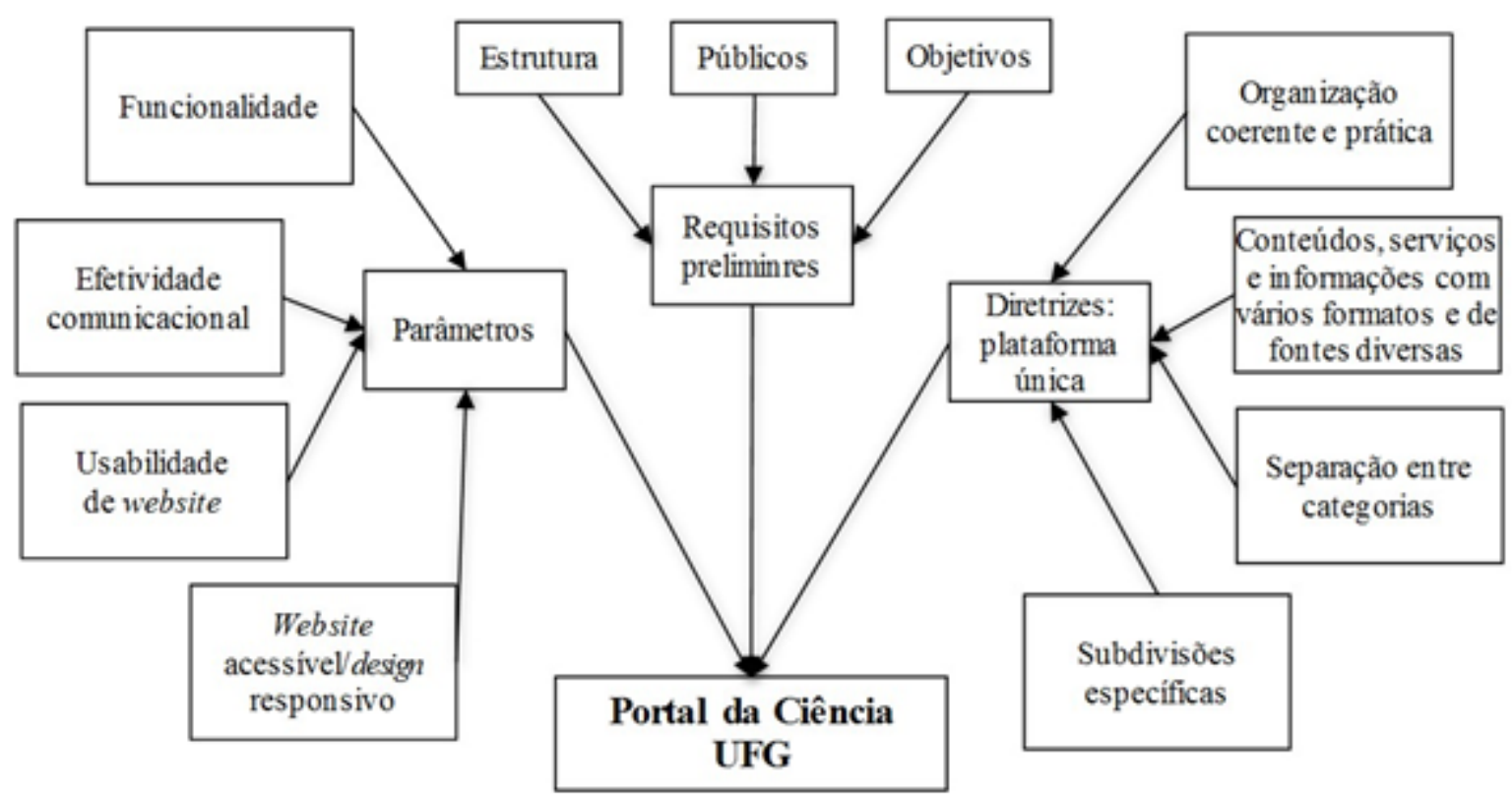

Fonte: Elaborado pelos autores a partir de Queiroz e Becker (2016); Spina (2016); Carmo (2015); Bueno (2014);

Pereira (2014); Rodrigues e Fachin (2010).

A escolha por formular uma proposta de Portal na internet como instrumento a mais para socialização da produção científica da UFG levou em conta se tratar de ferramenta de fácil acesso, que pode reunir e disseminar de maneira ágil e objetiva conteúdos diversos, em vários formatos, a distintas audiências. Além disso, o levantamento de dados realizado durante a pesquisa demonstrou que a UFG dispõe de ações, programas, políticas, iniciativas e espaços isolados relacionados à difusão científica que podem ser a base inicial e justificam a estruturação de uma plataforma única, ou seja, um Portal para agregar os conteúdos científicos produzidos em diferentes formatos e locais, no âmbito da UFG. 
Os objetivos principais a serem alcançados com a estruturação do Modelo de Portal para a Ciência da UFG são: integrar a produção de conhecimentos científicos da Universidade; articular produtores e divulgadores de ciência; e aumentar a visibilidade da pesquisa científica realizada na Instituição.

A viabilização da proposta, entretanto, requer a observação de alguns requisitos preliminares, entre eles, a necessidade de estrutura própria para criação e gestão do Portal, instalações físicas, recursos técnicos e espaço adequados, assim como pessoal qualificado e em quantidade suficiente para acompanhamento, desenvolvimento, atualização e promoção da plataforma.

Também devem ser levados em conta parâmetros relacionados a funcionalidade, efetividade comunicacional, usabilidade de website, design responsivo e website acessível. Sendo funcionalidade considerada a facilidade dos usuários realizarem tarefas, sem erros; efetividade comunicacional diz respeito a conexão entre informações apresentadas no Portal e os objetivos da instituição; usabilidade de website é atributo de qualidade relacionado à capacidade de grupos de usuários específicos navegarem pelos conteúdos com facilidade e atingindo seus objetivos; e website acessível/design responsivo é a possibilidade de acesso de qualquer pessoa, em qualquer tipo de tela, a todos os conteúdos apresentados.

Para garantir que a plataforma tenha um fluxo permanente e atualizado de informações lista-se a seguir, no Quadro 6, diretrizes que podem ser adotadas pela Universidade e elementos essenciais para integrar o Modelo de Portal para a Ciência da UFG.

Quadro 6 - Resumo das principais diretrizes a serem adotadas pela UFG e elementos essenciais ao Modelo de Portal para a Ciência.

\section{Diretrizes}

- Incorporação de um item específico nos projetos de pesquisa determinando que uma das ações ao final do trabalho precisa ser dar publicidade aos resultados obtidos;

- Autores de trabalhos científicos devem elaborar um pequeno resumo da temática pesquisa para divulgação ao público em geral;

- Estruturação de um banco de fontes/especialistas com a lista de pesquisadores comprometidos com a divulgação dos conhecimentos que produzem;

- Produtores de ciência e divulgadores devem dispor de uma ferramenta própria de interlocução que facilite o diálogo entre eles;

- Apresentação mais direta de centros, núcleos e pesquisas em desenvolvimento na Instituição;

- Divulgação das datas de defesa de teses e dissertações, acompanhada por pequenos textos explicativos sobre o estudo realizado;

- Divulgação mais ampla de eventos com temática científica congressos, seminários, semanas acadêmicas, palestras, atividades de extensão.

\section{Elementos}

- Apresentar na página inicial do Portal um menu que reúna conteúdos por afinidade para que possa ser instituída uma arquitetura de informações que garanta uma visão geral da plataforma;

- Disponibilizar ferramenta de busca no Portal que permita buscas simples e avançadas para que os usuários encontrem de maneira ágil e fácil a notícia/produto/serviço/espaço que precisa;

- Plataformas de interação (e-mails, contatos, fale conosco) entre o público internauta e a rede de atores envolvidos no processo de difusão científica da UFG, com espaço para receber sugestões, demandas e questionamentos, com a necessária apresentação de respostas;

- Possibilidade de criação de blogs com temática científica vinculados ao Portal e de espaços para artigos de opinião;

- Disponibilizar botões específicos para curtir, recomendar e compartilhar páginas e conteúdo para ajudar na propagação e divulgação do Portal;

- Implementar um canal específico de diálogo da imprensa, jornalistas e a mídia em geral, com o setor de divulgação do Portal para auxiliar na disseminação da produção científica da Universidade;

- Assegurar atualizações frequentes da plataforma;

- Apresentação dos conteúdos em formatos variados: notícias, entrevistas, vídeos, infográficos, artigos, ilustrações, podcast.

- Disponibilizar sistema de cadastro e distribuição de novos conteúdos para que os interessados possam receber as atualizações do Portal;

- Vincular o Portal a redes sociais digitais, com a disponibilização de conteúdos adequados a cada uma delas; 
- Organização dos produtos para apresentação no Portal com direcionamento de conteúdo aos grupos de maior interesse, de modo que a plataforma atenda variadas audiências: sociedade, alunos e pesquisadores.

Fonte: Elaborado pelos autores (2017)

Em princípio, a página inicial do Portal de Ciência da UFG poderia ser demonstrada como ilustra a Figura 2.

Figura 2 - Ilustração da interface inicial do Modelo de Portal para a Ciência da UFG.
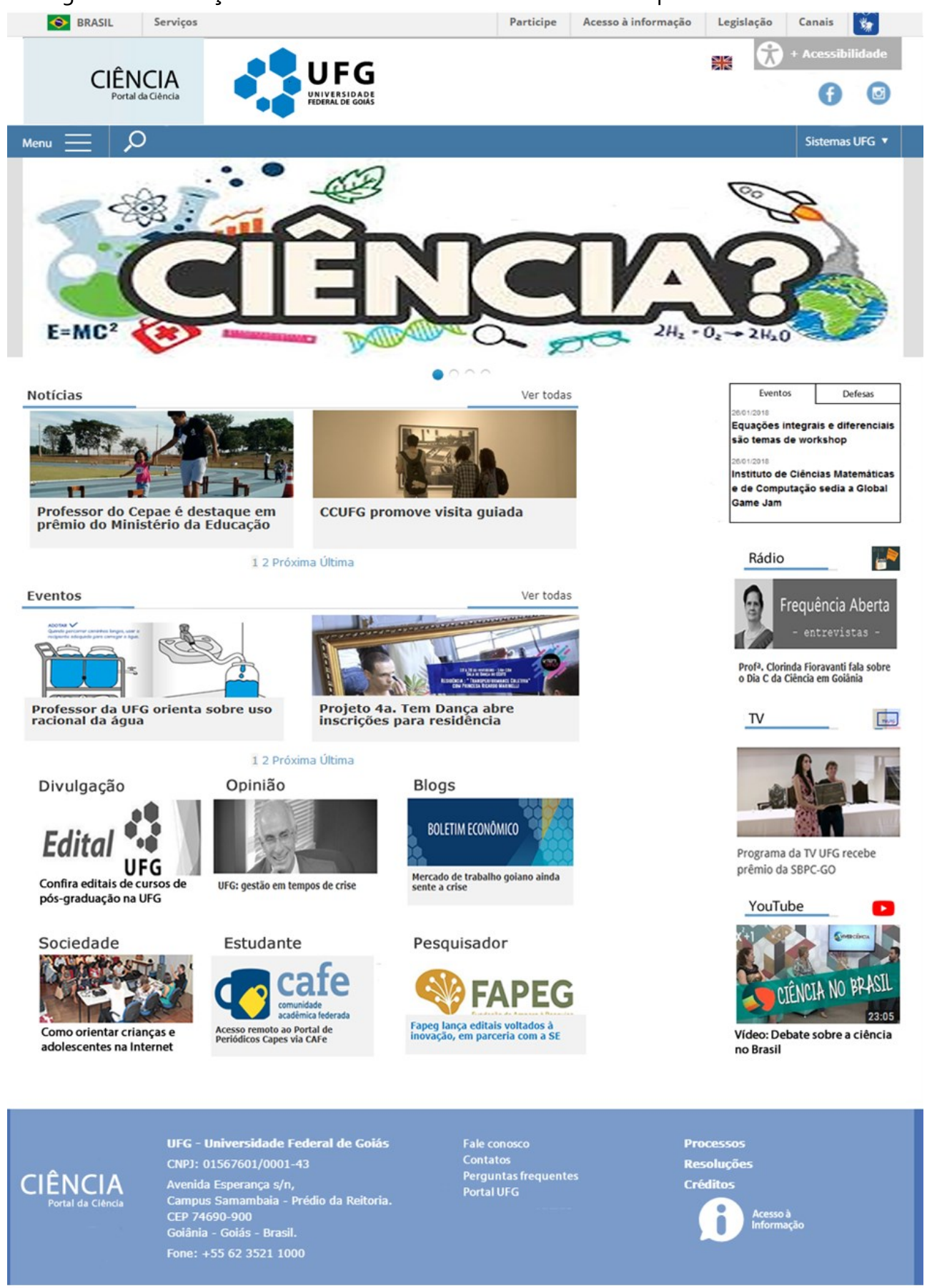

Fonte: Elaborado pelos autores (2017).

Para implementação desse Modelo de Portal para a Ciência pela UFG é necessário salientar que, antes, a proposta deverá ser apresentada e aprovada pela Administração Central da Universidade. Lembrando que não 
se trata de uma proposta fechada, de uma ferramenta finalizada, mas da construção de um instrumento a mais para socialização da produção científica da UFG que deverá ser partilhado com a comunidade da Universidade, de modo que a iniciativa seja, efetivamente, apropriada pelos vários setores da Instituição e possa ser estruturada e formalizada.

\section{${ }_{5}$ CONCLUSÃO}

A pesquisa desenvolvida permitiu identificar que nos documentos institucionais da UFG há diretrizes em favor da socialização dos conhecimentos gerados na Instituição e que para colocar em prática essas diretrizes a Universidade dispõe de programas, políticas, ações e atividades. Entretanto, na observação e análise realizada nos sítios das estruturas centrais, dos veículos de comunicação e das principais iniciativas da UFG para fazer circular informações sobre ciência constata-se que há desafios a serem superados para que a produção científica da Instituição ganhe maior visibilidade e alcance a sociedade em geral, sobretudo porque as atividades de difusão científica da Universidade estão fragmentadas e dispersas, muitas vezes restritas a ambientes isolados.

O estudo também demonstrou que o mecanismo que mais tem se destacado enquanto alternativa para aumentar e melhorar a transmissão de saberes científicos é a internet, por meio de sites e portais. Assim, foi possível chegar a parâmetros, requisitos e diretrizes que orientaram a elaboração de um Modelo de Portal para a Ciência para a UFG.

A partir de aspectos capturados no referencial teórico e no levantamento de dados, conclui-se que um Portal para divulgação científica apresenta-se como uma ferramenta viável e com potencial para socializar de maneira mais ampla, fácil e ágil os conhecimentos científicos gerados no interior da UFG, uma vez que esse tipo de plataforma possibilita a reunião de diferentes conteúdos de ciência, produzidos em vários formatos e locais, em toda a Universidade.

O Modelo de Portal para a Ciência elaborado neste estudo não se propôs a oferecer um design final e acabado ou as tecnologias para viabilizar a plataforma. A perspectiva foi apontar direcionamentos a serem observados, analisados e discutidos pela UFG ou outros centros produtores de ciência de maneira que um Portal para a Ciência possa cumprir as funções de articular atores e reunir conteúdos, deixando mais acessível - a variadas audiências - a produção científica das instituições.

Trabalhos futuros poderão estudar adaptações e a validação dessa proposta como possibilidade de melhorar a interlocução das instituições científicas com seus públicos, internos e externos.

\section{REFERÊNCIAS}

BOMFÁ, Cláudia Regina Ziliotto; CASTRO, João Ernesto. Desenvolvimento de revistas científicas em mídia digital-o caso da Revista Produção Online. Ciência da informação, v. 33, n. 2, p. 39-48, 2004.

BORTOLIERO, Simone. [2011]. Os desafios do Jornalismo Cientifico no século XXI. Disponível em: <https://goo.gl/UKUvcV>. Acesso em: 26 mar. 2017.

BRASIL. Ministério da Ciência, Tecnologia, Inovações e Comunicações (MICTIC). Relatório. Percepção Pública da Ciência e Tecnologia no Brasil. Resultados da enquete de 2010. Disponível em: <https://goo.gl/yıKcvX>. Acesso em: 9 maio 2017.

Relatório. Percepção Pública da Ciência e Tecnologia no Brasil. Resultados da enquete de 2006. Disponível em: <https://goo.gl/vD1r2F>. Acesso em: 9 maio 2017.

MCT; CNPq; MAST. [1987]. O que o Brasileiro Pensa da Ciência e Tecnologia. Disponível em: https://goo.gl/Lj5E6Y. Acesso em: 9 maio 2017. 
BUENO, Wilson da Costa. A Divulgação da Produção Científica no Brasil: A Visibilidade da Pesquisa nos Portais das Universidades Brasileiras. Ação Midiática-Estudos em Comunicação, Sociedade e Cultura., p. 1-15, n. 7, 2014 .

Prefácio. In: PORTO, Cristiane de Magalhães (Org). Difusão e cultura científica: alguns recortes [online]. Salvador: EDUFBA, 2009a. p. 13-22. Disponível em: SciELO Books <http://books.scielo.org>. Acesso em: 10 dez. 2016.

Jornalismo científico: revisitando o conceito. In: PORTO, Cristiane de Magalhães (org). Difusão e cultura cientifica: alguns recortes [online]. Salvador: EDUFBA, 200gb. p. 113-125. Disponível em: SciELO Books <http://books.scielo.org>. Acesso em: 10 dez. 2016.

CALDAS, Graça. Divulgação científica e relações de poder. Informação \& Informação, v. 15, n. 1 esp., p. 31-42, 2010.

CANDOTTI, Ennio. Ciência na educação popular. In: Massarani, Luisa.; Moreira, Ildeu de Castro Moreira; Brito, Fátima. (Org.). Ciência e público: caminhos da divulgação científica no Brasil. Rio de Janeiro: Casa da CiênciaCentro Cultural de Ciência e Tecnologia da UFRJ, 2002. p. 15-24.

CARIBÉ, Rita de Cássia do Vale. Comunicação científica: reflexões sobre o conceito. Informação \& Sociedade, v. 25, n. 3, p. 89-104, 2015.

CARMO, Vanessa Aparecida do. A divulgação científica nas universidades do Grande ABC: inovações ou repetição de formatos? 2015.Dissertação (mestrado), 106 p. USCS-Universidade Municipal de São Caetano do Sul. São Caetano do Sul, SP.

CARVALHO, Anabela; CABECINHAS, Rosa. Comunicação da ciência: perspectivas e desafios. Comunicação e Sociedade, n. 6, p. 5-10, 2004 .

CASTELFRANCHI, Yurij. As serpentes e o bastão: tecnociência, neoliberalismo e inexorabilidade. 2008. Tese (Doutorado) - Universidade Estadual de Campinas, Campinas, SP.

CENTRO DE GESTÃO E ESTUDOS ESTRATÉGICOS (CGEE). [2015]. Percepção pública da ciência e tecnologia 2015 - Ciência e tecnologia no olhar dos brasileiros. Disponível em: <>http://percepcaocti.cgee.org.br/. Acesso em: 10 abr. 2017.

CHIARINI, Túlio; VIEIRA, Karina Pereira. Universidades como produtoras de conhecimento para o desenvolvimento econômico: sistema superior de ensino e as políticas de CT\&I. Rev. Bras. Econ. [online]. 2012, v. 66, n. 1, p. 117-132. Disponível em: </http://dx.doi.org/10.1590/So034-71402012000100006>. Acesso em: 29 jan. 2017.

DUARTE, Jorge. Da divulgação científica à comunicação. [2004]. On-line - Associação Brasileira de Jornalismo Científico, 2004. Disponível em: <https://goo.gl/ALP7Tk>. Acesso em: 9 mar. 2017.

DUNWOODY, Sharon. Science Journalism - Prospects in the digital age. In:BUCCHI, Massimiano; TRENCH, Brian (Org.). Routledge Handbook of Public Communication of Science and Technology - Second Edition. New York: Routledge Taylor \& Francis Group, 2014. p. 27-39. Disponível em: <https://www.routledgehandbooks.com/doi/10.4324/9780203483794.ch32. Acesso em: 3 jun. 2017.

INSTITUTO BRASILEIRO DE INFORMAÇÃO EM CIÊNCIA E TECNOLOGIA (IBICT). [2017]. Quem somos. Disponível em: <http://www.canalciencia.ibict.br/menu/quemsomos/editorial.html>. Acesso em: 9 set. 2017.

LÓPEZ-PÉREZ, Lourdes; OLVERA-LOBO, María-Dolores. Comunicación pública de la ciencia a través de la web 2.0. El caso de los centros de investigación y universidades públicas de España. El profesional de la información, v. 25, n. 3, p. 441-448, 2016. 
MINAYO, Maria Cecília de Souza. O Desafio do Conhecimento: pesquisa qualitativa em saúde. 14. ed. São Paulo: Hucitec, 2014. 407 p.

MUELLER, Suzana Pinheiro Machado. O crescimento da ciência, o comportamento científico e a comunicação científica: algumas reflexões. Revista da Escola de Biblioteconomia da UFMG, v. 24, n. 1, p. 63-84, 1995.

OLIVEIRA, Fabiola. Comunicação pública e cultura científica. Parcerias Estratégicas, v. 6, n. 13, p. 201-208, 2001.

OLIVEIRA, Maxwell Ferreira de. Metodologia científica: um manual para a realização de pesquisas em Administração. Catalão: UFG, 2011. 72 p.: il. Manual (pós-graduação) - Universidade Federal de Goiás, 2011.

PETERS, Hans Peter et al. Public communication of science 2.0: Is the communication of science via the "new media" online a genuine transformation or old wine in new bottles?. EMBO reports, p. e201438979, 2014.

PEREIRA, Isabel Cristina Luz. Ciência 2.o: Comunicar ciência na era digital-da experiência à reflexão. 2012. Tese (Doutorado) - Universidade do Porto, Portugal.

PEREIRA, Marcos Rogério. Produção e divulgação científica na Internet: uma perspectiva tecnológica do projeto de pesquisa em mudanças climáticas AlcScens. 2014. 153f. Dissertação (Mestrado) - Universidade Estadual de Campinas, Campinas, SP.

PINHEIRO, Lena Vania Ribeiro. Internet, ciência e sociedade: o que mudou para pesquisadores e cidadãos? ComCiência, Campinas, n. 139, p. 0-0, 2012.

PINHEIRO, Lena Vania Ribeiro; SILVA, Márcia Rocha da. Análise de metrias para dimensionar o acesso, o uso e a repercussão do portal de divulgação científica CanalCiência. In: CONGRESSO BRASILEIRO DE JORNALISMO CIENTÍFICO, 9., 2007, São Paulo. Anais... 2007. p. 1-15.

QUEIROZ, Giuliana Batista Rodrigues; BECKER, Valdecir. The Dissemination of Science and Science Journalism in Brazilian Universities: Analyzing Strategies that Facilitate Access to Science \& Technology. Brazilian Journalism Research, v. 12, n. 3, p. 170-189, 2016.

RODRIGUES, Rosângela Schwarz; FACHIN, Gleisy Regina Bories. Portal de periódicos científicos: um trabalho multidisciplinar. Transinformação-ISSNe 23180889, v. 22, n. 1, p. 35-45, 2010.

SANTOS, Gildenir Carolino. Sustentabilidade e Visibilidade da Produção Científica: A Construção do Portal de Periódicos Eletrônicos Científicos da Unicamp. In: SEMINÁRIO NACIONAL DE BIBLIOTECAS UNIVERSITÁRIAS, Manaus, Amazônia, Brasil. Anais do SNBU. Manaus: UFAM, 2016.

SANTOS, Sônia Maria Dos. O desempenho das Universidades Brasileiras nos Rankings Internacionais: áreas de destaque da produção científica brasileira. 2015. Tese (Doutorado em Cultura e Informação) - Escola de Comunicação e Artes, Universidade de São Paulo, São Paulo.

SPINA, Tatiana Gladcheff Zanon. Divulgação científica por meio de ferramentas digitais: estudo de caso do portal do Instituto de Física de São Carlos (IFSC/USP). 2016. 95 f. Dissertação (Mestrado) -- Universidade Federal de São Carlos, São Carlos, SP.

TRIVIÑOS, Augusto Nibaldo Silva. Introdução à pesquisa em ciências sociais: a pesquisa qualitativa em educação. São Paulo: Atlas, 1987.

UNESCO. Relatório. 2015. Disponível em: <https://en.unesco.org/unesco_science_reportz. Acesso em: 30 jan. 2017.

UNIVERSIDADE FEDERAL DE GOIÁS (UFG). Plano Desenvolvimento Institucional (PDI 2018-2022). [2017a]. Disponível em: <https://www.ufg.br/up/1/o/PDI_UFG_-

_Plano_de_desenvolvimento_institucional_2018-2022.pdf>. Acesso em: 8 dez. 2017. 
Resolução CONSUNI No 18/2017. [2017b]. Disponível em: <https://www.ufg.br/n/63397-resolucoes>. Acesso em: 23 set. 2017.

Plano Desenvolvimento Institucional (PDI 2011-2017). [2015a].

Disponível em:

<https://prodirh.ufg.br/up/64/o/PDI_Atualizado_dez2013B.pdf?1393439472>. Acesso em: 22 set. 2017.

Regimento Geral. [2015b]. Disponível em: https://www.ufg.br/up/1/o/RESOLUCAO-3CO-01-2015.pdf. Acesso em: 22 set. 2017.

Estatuto. [2014a]. Disponível em: <https://www.ufg.br/up/1/o/ESTATUTO_da_UFG_2014.pdf>. Acesso em: 22 set. 2017.

Plano de Gestão 2014-2017. [2014b]. Disponível em:

<https://www.ufg.br/up/1/o/Plano_de_Gest\%C3\%A30_2014_2017.xps>. Acesso em: 22 set. 2017.

Plano Diretor de tecnologia da Informação (PDTI 2014 -2015).[2014C]. Disponível em: <https://prodirh.ufg.br/up/64/o/PDTI_Final.pdf?1404822477>. Acesso em: 22 set. 2017.

Carta de Serviços ao Cidadão. [2012]. Disponível em: <http://www.ufg.br/up/1/o/CARTA_DE_SERVI_OS_AO_CIDAD_O_timbre.pdf>. Acesso em: 22 set. 2017.

VALERIO, Palmira Moricone. Comunicação Científica e Divulgação: O Público na Perspectiva da Internet. In: PINHEIRO, Lena Vania Ribeiro; OLIVEIRA, Eloisa da Conceição Príncipe de (Org.). Múltiplas facetas da comunicação e divulgação científicas: transformações em cinco séculos Brasília: IBICT, 2012. p $150-167$.

VALERIO, Palmira Moriconi; PINHEIRO, Lena Vania Ribeiro. Da comunicação científica à divulgação. Transinformação, v. 20, n. 2, P. 159-169, 2008.

VOGT, Carlos. A Espiral da cultura científica. [2003]. Disponível em: <https://goo.gl/OywR4s>. Acesso em: 23 dez. 2016. 